\title{
Volatility Prediction: A Study with Structural Breaks
}

\author{
Dilip Kumar \\ Indian Institute of Management Kashipur, Kashipur, India \\ Email: dilip.kumar@iimkashipur.ac.in
}

How to cite this paper: Kumar, D. (2018) Volatility Prediction: A Study with Structural Breaks. Theoretical Economics Letters, 8, 1218-1231.

https://doi.org/10.4236/tel.2018.86080

Received: January 6, 2018

Accepted: April 20, 2018

Published: April 23, 2018

Copyright (C) 2018 by author and Scientific Research Publishing Inc. This work is licensed under the Creative Commons Attribution International License (CC BY 4.0).

http://creativecommons.org/licenses/by/4.0/

\begin{abstract}
We incorporate the impact of structural breaks in the unbiased unconditional volatility as proposed by Kumar and Maheswaran [1] with a conditional autoregressive range (CARR) model. The findings of the proposed framework are compared with the findings based on the volatility forecasts of the GARCH model with and without structural breaks in volatility. Our findings based on the analysis on S\&P 500, FTSE 100, SZSE Composite and FBMKLCI indices indicate that the proposed framework effectively captures the dynamics of conditional volatility and provides better out-of-sample forecasts relative to GARCH models with and without structural breaks in volatility.
\end{abstract}

\section{Keywords}

CARR Model, AddRS Estimator, Volatility Forecast Evaluation, GARCH Family of Models

\section{Introduction}

The volatility of assets plays a very important role in investment decisions making, portfolio implementation and management, option pricing and risk measurement. There are various ways to estimate the daily unconditional volatility. Based on the kind of data available, different proxies for the daily volatility are available in the literature. The demeaned squared return and absolute return are the popular proxies of volatility based on daily closing prices of the tradable assets. However, these estimates of daily volatility are noisy in nature [2]. Realized volatility is another popular unconditional volatility estimator and is estimated by taking the sum of squares of the high-frequency returns. However, the high-frequency data are expensive to obtain and are influenced by market microstructure issues. There exist many volatility estimators based on the opening, high, low and closing prices. The highly efficient and unbiased properties of 
these volatility estimators in comparison to the squared returns and absolute returns make them an attractive alternative to estimate the daily volatility of the market. These include the volatility estimators proposed by Parkinson [3], Garman and Klass [4], Rogers and Satchell [5], Yang and Zhang [6] and Kumar and Maheswaran [1]. The opening, high, low and closing prices contain more information than the closing prices alone and are available for most of the traded assets and indices.

In this paper, we use AddRS with CARR to conditionally model the AddRS volatility estimator. We also incorporate the adjustment for the presence of structural breaks in the model using exogenous dummy variables representing different regimes. These infrequent regime shifts in volatility may be due to major domestic as well as global financial, macroeconomic and political events [7] [8] [9] [10]. Such structural breaks in volatility can affect the intensity and the direction of flow of the information between markets [11]. There exist various approaches to incorporate the impact of structural breaks in volatility for modelling and generating forecasts of the daily volatility. The evidence of long memory in the market is also influenced by the presence of structural breaks in the series [12].

In this study, we use the framework as proposed by Inclan and Tiao [13] (hereafter referred as IT-ICSS) to detect the presence of structural breaks in the unconditional volatility (AddRS estimator). Next, we incorporate the impact of structural breaks in the AddRS estimator in the CARR model and analyze the influence of such structural breaks in volatility on volatility persistence. We use CARR-B to represent the CARR model with structural breaks in volatility, CARR to represent the plain vanilla CARR model, GARCH-B to represent the GARCH model with volatility breaks and GARCH to represent the plain vanilla GARCH model. The study does not compare the performance of the model in forecasting volatility with other models from the GARCH family. Further study can be undertaken to compare the results with the results from the other models from the GARCH family.

The remainder of this paper is organized as follows: Section 2 presents the brief literature review. Section 3 presents the methodology used in this study. Section 4 describes the data and discusses the preliminary analysis. Section 5 reports the empirical results. Section 6 describes the conclusion with a summary of main findings.

\section{Brief Literature Review}

The Generalized Autoregressive Conditional Heteroskedasticity (GARCH) family of models including EGARCH, GJR-GARCH and much more are quite popular to conditionally model the squared returns and to capture the dynamics of volatility. However, there exist evidence indicating that the conditional volatility based on the opening, high, low and closing prices perform much better than the GARCH based conditional volatility [14] [15] [16]. Chou [14] proposes the Conditional Autoregressive Range Model (CARR) to analyze the dynamics of 
volatility based on opening, high, low and closing prices and finds that the CARR model generate better forecasts of volatility than the return based volatility models, that is, the models from the GARCH family. Brandt and Jones [15] propose another model to capture the dynamics in extreme value volatility estimator (range based volatility) based on the Exponential Generalized Autoregressive Conditional Heteroskedasticity (EGARCH) model. The findings indicate that the proposed models effectively generate better forecasts of volatility than the return based volatility models. They find that the range based conditional volatility models can better forecast the volatility over longer horizon upto 1 year in comparison to the similar forecast by GARCH based forecasts. Li and Hong [17] propose the range-based autoregressive volatility model and their findings are also in line with that of Chou [14] and Brandt and Jones [15] that range based conditional volatility exhibit good performance in forecasting future volatility. Kumar [16] analyze the volatility forecasting performance of the CARR model based on the Rogers and Satchell [5] (RS) estimator in presence of structural breaks and find that the RS estimator based CARR model generates more accurate forecasts of volatility than the return based volatility models. In this paper, we propose the use of CARR model in modeling the unbiased AddRS volatility estimator and in generating more accurate forecasts of realized volatility.

\section{Methodology}

\subsection{Inclan and Tiao's (1994) (IT-ICSS) Algorithm}

Suppose $\varepsilon_{t}$ is a zero mean series with unconditional variance $\sigma^{2}$. Suppose the variance for each regime is given by $\tau_{j}^{2}$, where $j=0,1, \cdots, N_{T}$ and $N_{T}$ is the total number of sudden changes in volatility in $T$ observations, and $1<k_{1}<k_{2}<\cdots<k_{N T}<T$ are the change points.

$$
\begin{array}{cc}
\sigma_{t}^{2}=\tau_{0}^{2} & \text { for } 1<t<\kappa_{1} \\
\sigma_{t}^{2}=\tau_{1}^{2} & \text { for } \kappa_{1}<t<\kappa_{2} \\
\sigma_{t}^{2}=\tau_{N T}^{2} & \text { for } \kappa_{N T}<t<T
\end{array}
$$

In order to estimate the presence of sudden changes in variance and the time point of each variance shift, we use a cumulative sum of squares procedure. The cumulative sum of the squared observations from the start of the series to the $k^{\text {th }}$ point in time is given as:

$$
C_{k}=\sum_{t=1}^{k} \varepsilon_{t}^{2}
$$

where $k=1, \cdots, T$. The $D_{k}(\mathrm{IT})$ statistics is given as:

$$
D_{k}=\left(\frac{C_{k}}{C_{T}}\right)-\frac{k}{T}, k=1, \cdots, T \text { with } D_{0}=D_{T}=0
$$

where $C_{T}$ is the sum of squared residuals from the whole sample period.

If there are no sudden changes in the variance of the series then the $D_{k}$ statis- 
tic oscillates around zero and when plotted against $k$. On the other hand, if there are sudden changes in the variance of the series, then the $D_{k}$ statistics values drift either above or below zero. The 95th percentile critical value for the asymptotic distribution of $\max _{k} \sqrt{(T / 2)\left|D_{k}\right|}$ is \pm 1.358 . If $\max _{k} \sqrt{(T / 2)\left|D_{k}\right|}$ violates the confidence band then a sudden change in variance is identified.

\subsection{The AddRS Unbiased Volatility Estimator}

Kumar and Maheswaran [1] derive a reflection principle for a random walk and proposed the unbiased AddRS volatility estimator. Suppose $O_{t}, H_{t}, L_{t}$ and $C_{t}$ are the opening, high, low and closing prices of an asset on day $t$. Define:

$$
\begin{gathered}
b_{t}=\log \left(\frac{H_{t}}{O_{t}}\right) \\
c_{t}=\log \left(\frac{L_{t}}{O_{t}}\right) \\
x_{t}=\log \left(\frac{C_{t}}{O_{t}}\right)
\end{gathered}
$$

Let $u_{t}=2 b_{t}-x_{t}$ and $v_{t}=2 c_{t}-x_{t}$. Hence, the bias corrected extreme value estimators are given by:

$$
\text { Add } u x=\frac{1}{2}\left(u_{t}^{2}-x_{t}^{2}\right)+x_{t}^{2} \cdot \mathbf{1}_{\left\{b_{t}=0 \text { or } x_{t}=b_{t}\right\}}
$$

and

$$
\operatorname{Add} v x=\frac{1}{2}\left(v_{t}^{2}-x_{t}^{2}\right)+x_{t}^{2} \cdot \mathbf{1}_{\left\{c_{t}=0 \text { or } x_{t}=c_{t}\right\}}
$$

Therefore, the unbiased AddRS estimator, as proposed by Kumar and Maheswaran [1], is given as:

$$
\text { AddRS }=\frac{1}{2}[\text { Add } u x+\text { Add } v x]
$$

\subsection{Conditional Autoregressive Range (CARR) Model}

Chou (2005) proposed the CARR model to study the dynamic nature of the range. Here, we propose the use of AddRS estimator in place of range in CARR model because it is unbiased regardless of the drift parameter. The specification of the standard $\operatorname{CARR}(p, q)$ model for the $\operatorname{AddRS~estimator~is~given~as:~}$

$$
\begin{aligned}
& \operatorname{AddRS}_{t}=\lambda_{t} \varepsilon_{t}, \quad \varepsilon_{t} \mid I_{t-1} \sim \exp (1, .) \\
& \lambda_{t}=\omega+\sum_{i=1}^{q} \alpha_{i} \operatorname{AddRS}_{t-i}+\sum_{j=1}^{p} \beta_{i} \lambda_{t-j}
\end{aligned}
$$

where AddRS $_{t}$ is the AddRS estimator as given in Equation (3), $\lambda_{t}$ is the conditional mean of the AddRS and $\varepsilon_{t}$ is the innovation term, that is, the normalized AddRS estimator $\left(\varepsilon_{t}=\operatorname{AddRS}_{t} / \lambda_{t}\right)$, which is assumed to follow the exponential distribution with unit mean. 


\subsection{Combined Model of Sudden Changes with CARR Model}

The $\operatorname{CARR}(p, q)$ model with volatility regimes based on the AddRS estimator can be expressed as follows:

$$
\begin{gathered}
\text { AddRS }_{t}=\lambda_{t} \varepsilon_{t}, \quad \varepsilon_{t} \mid I_{t-1} \sim \exp (1, .) \\
\lambda_{t}=\omega+d_{1} D_{1}+\cdots+d_{n} D_{n}+\sum_{i=1}^{q} \alpha_{i} \operatorname{AddRS~}_{t-i}+\sum_{j=1}^{p} \beta_{i} \lambda_{t-j}
\end{gathered}
$$

where $D_{1}, \cdots, D_{n}$ are the dummy variables taking the value of 1 from each point of sudden change in the unconditional variance onwards and 0 elsewhere.

\section{Data and Preliminary Results}

\subsection{Dataset}

We use weekly opening, high, low and closing prices of Standard \& Poor 500 (S\&P 500), FTSE 100, SZSE Composite (hereafter, SZSEC) and FBMKLCI which include two developed and two emerging markets. All the data have been obtained from the Bloomberg database. The period of study is from April 1996 to June 2017.

\subsection{Descriptive Statistics}

Table 1 reports the descriptive statistics of the AddRS estimator and the return series for the given market indices. The Chinese market appears to be highly volatile than other markets based on the highest value of the average AddRS estimator followed by the UK, the US and Malaysian market. However, the volatility of volatility is the highest for the Malaysian market (based on standard deviation of the AddRS estimator) followed by the Chinese market and the developed markets. All the AddRS series exhibit significant positive skewness and excess kurtosis. However, except for Malaysian market, all other markets returns exhibit significant negative skewness and excess kurtosis. The significant values of the Ljung Box statistic up to 20 lags indicate the presence of significant autocorrelation up to 20 lags in all AddRS and return series. Moreover, the significant value of the $\mathrm{ARCH}(10)$ statistic indicates the presence of significant heteroscedasticity in all the AddRS and return series.

\section{Empirical Results}

\subsection{Detection of Structural Breaks in the AddRS Estimator and Squared Return}

First, we identify the presence of volatility regimes in the AddRS estimator and the squared return using IT-ICSS approach. Table 2 and Table 3 report the breaks identified in the AddRS estimator and squared return respectively.

\subsection{Estimation of the CARR Model Based on the AddRS and GARCH Model Based on Returns}

We estimate the CARR model based on the AddRS estimator with and without structural breaks in the AddRS estimator. The given models are reported in 
Table 1. Descriptive statistics of the AddRS estimator (RS) and returns $\left(r_{t}\right)$.

\begin{tabular}{ccccccccc}
\hline & \multicolumn{9}{c}{ AddRS } & \multicolumn{5}{c}{ Return } \\
\cline { 2 - 9 } & S\&P 500 & FTSE 100 & SZSEC & FBMKLCI & S\&P 500 & FTSE 100 & SZSEC & FBMKLCI \\
\hline Mean & 1.270 & 1.444 & 1.755 & 1.132 & 0.119 & 0.063 & 0.156 & 0.039 \\
Median & 0.552 & 0.659 & 0.764 & 0.296 & 0.274 & 0.214 & 0.242 & 0.101 \\
Min & 0.008 & 0.014 & 0.000 & 0.001 & -20.828 & -15.297 & -25.937 & -13.720 \\
Max & 45.713 & 59.976 & 31.891 & 54.265 & 10.182 & 13.588 & 17.675 & 28.109 \\
Stdev & 2.634 & 3.016 & 3.039 & 3.308 & 2.363 & 2.390 & 3.704 & 2.938 \\
Skewness & $8.703 \#$ & $9.901 \#$ & $4.709 \#$ & $9.100 \#$ & $-0.956 \#$ & $-0.441 \#$ & $-0.601 \#$ & $1.269 \#$ \\
Kurtosis & $116.428 \#$ & $154.646 \#$ & $33.133 \#$ & $112.604 \#$ & $10.627 \#$ & $7.064 \#$ & $8.109 \#$ & $21.055 \#$ \\
JB stat & $607965.2 \#$ & $1079767.2 \#$ & $46014.6 \#$ & $569893.7 \#$ & $2851.670 \#$ & $797.433 \#$ & $1270.789 \#$ & $15332.112 \#$ \\
Q(20) & $1149.728 \#$ & $856.365 \#$ & $596.870 \#$ & $1280.295 \#$ & $55.247 \#$ & $42.985 \#$ & $43.736 \#$ & $83.904 \#$ \\
ARCH(10) & $350.873 \#$ & $138.080 \#$ & $39.573 \#$ & $245.005 \#$ & $99.229 \#$ & $121.457 \#$ & $95.687 \#$ & $124.006 \#$ \\
\hline
\end{tabular}

\#means significant at 1\% level. Note that Stdev represents the standard deviation, JB stat represents the Jarque Bera statistic, $\mathrm{Q}(20)$ indicates the Ljung-Box Q statistic up to 20 lags and $\mathrm{ARCH}(10)$ indicates the Lagrange multiplier test for conditional heteroskedasticity up to 10 lags.

Table 2. Breaks detected in the AddRS estimator.

\begin{tabular}{|c|c|c|c|}
\hline Index & Number of Breaks & Break Date Detected & Reason \\
\hline \multirow{4}{*}{ S\&P 500} & \multirow{4}{*}{4} & 26-01-2000 & The internet bubble \\
\hline & & $16-04-2003$ & Post-internet bubble bursting impact \\
\hline & & 29-08-2007 & Global Financial Crisis \\
\hline & & $15-09-2010$ & Bull rally after global financial crisis \\
\hline \multirow{4}{*}{ FTSE 100} & \multirow{4}{*}{4} & 09-02-2000 & The internet bubble \\
\hline & & $23-04-2003$ & Post-internet bubble bursting impact \\
\hline & & 29-08-2007 & Global financial crisis \\
\hline & & 08-09-2010 & Bull rally after global financial crisis \\
\hline \multirow{2}{*}{ SZSEC } & \multirow{2}{*}{2} & 26-04-2006 & - \\
\hline & & 23-09-2009 & Bull rally after global financial crisis \\
\hline \multirow{2}{*}{ FBMKLCI } & \multirow{2}{*}{2} & 04-04-2001 & Internet bubble \\
\hline & & 29-07-2009 & Bull rally after global financial crisis \\
\hline
\end{tabular}

Equations (4) and (5). The models for incorporating the impact of structural breaks in squared return based on the GARCH model is given as:

$$
\begin{gathered}
\varepsilon_{t}=z_{t} \sigma_{t}, \quad z_{t} \sim N(0,1) \\
\sigma_{t}^{2}=\omega+d_{1} D_{1}+\cdots+d_{n} D_{n}+\alpha_{1} \varepsilon_{t-1}^{2}+\beta_{1} \sigma_{t-1}^{2},
\end{gathered}
$$

where $D_{1}, \cdots, D_{n}$ are the dummy variables taking a value of 1 for the given volatility regime and 0 elsewhere.

The GARCH model without any volatility regimes is given as:

$$
\begin{gathered}
\varepsilon_{t}=z_{t} \sigma_{t}, \quad z_{t} \sim N(0,1) \\
\sigma_{t}^{2}=\omega+\alpha_{1} \varepsilon_{t-1}^{2}+\beta_{1} \sigma_{t-1}^{2},
\end{gathered}
$$

Table 4 presents the parameter estimates and diagnostics for the CARR model with and without volatility breaks and GARCH model with and without volatility breaks for all the given indices under study. 
Table 3. Breaks detected in the squared returns.

\begin{tabular}{|c|c|c|c|}
\hline Index & Number of Breaks & Break Date Detected & Reason \\
\hline \multirow{4}{*}{ S \& P 500} & \multirow{4}{*}{4} & $15-03-2000$ & Internet bubble \\
\hline & & 04-06-2003 & Post-internet bubble bursting impact \\
\hline & & 03-09-2008 & Late 2000 's financial crisis \\
\hline & & $14-12-2011$ & European debt crisis \\
\hline \multirow{3}{*}{ FTSE 100} & \multirow{3}{*}{3} & 19-03-2003 & Post-internet bubble bursting impact \\
\hline & & $17-10-2007$ & Sub-prime crisis \\
\hline & & $30-11-2011$ & European debt crisis \\
\hline \multirow{3}{*}{ SZSEC } & \multirow{3}{*}{3} & 07-07-1999 & Internet bubble \\
\hline & & $15-11-2006$ & - \\
\hline & & 27-01-2010 & Bull rally after global financial crisis \\
\hline \multirow{3}{*}{ FBMKLCI } & \multirow{3}{*}{3} & 18-08-1999 & Internet bubble \\
\hline & & $15-01-2003$ & Post-internet bubble bursting impact \\
\hline & & 22-07-2009 & Bull rally after global financial crisis \\
\hline
\end{tabular}

The standard errors of the parameters of the CARR models based on the AddRS estimator are smaller in magnitude than the standard errors of the corresponding parameters from the GARCH models which confirms the finding of Brandt and Jones [15] regarding the unbiased and highly efficient nature of the extreme value volatility estimators. Results indicate that the short-term volatility component and long-term volatility components (based on significant values of $\alpha_{1}$ and $\beta_{1}$ ) influence the current volatility distinctly and contribute significantly in defining the dynamics of current volatility. We also observe a decline in volatility persistence when structural breaks in volatility are incorporated in the models (for both the CARR and the GARCH models). The volatility persistence in the CARR model without any structural breaks in volatility ranges between 0.994 (for FBMKLCI) and 0.953 (for FTSE 100). However, when volatility breaks are accounted in the CARR model, the volatility persistence experience decline and lies between 0.862 (for FTSE 100) and 0.623 (for S\&P 500). We observe a larger decline in the value of volatility persistence in CARR model with breaks (with respect to the vanilla CARR model) than what is observed in the GARCH model with breaks (with respect to vanilla GARCH model). This confirms the findings of Lamoureux and Lastrapes [18], Malik [19], Kumar and Maheswaran [7] and much more that accounting for the volatility regimes in the conditional volatility models reduce the persistence in conditional volatility. The Ljung Box statistic up to 10 lags for the standardized residuals and the squared standardized residuals for all the four models (CARR, CARR-B, GARCH, GARCH-B) confirm no autocorrelation the standardized residuals except the GARCH and GARCH-B models for SZSEC. The results based on the ARCH(10) statistic indicate the presence of no heteroscedasticity in the standardized residuals based on all four specifications. Overall, results indicate that the CARR and CARR-B models are better able to capture the dynamics of volatility based on lowest values of the standard errors of the parameters when compared with respective GARCH models. 
Table 4. Parameter estimates of the CARR and GARCH models with and without volatility breaks.

\begin{tabular}{|c|c|c|c|c|c|c|c|c|}
\hline & $\omega$ & $\alpha_{1}$ & $\beta_{1}$ & $\alpha_{1}+\beta_{1}$ & LLF & $\mathrm{Q}(10)$ & Qs(10) & $\operatorname{ARCH}(10)$ \\
\hline \multicolumn{9}{|l|}{ S\&P 500} \\
\hline \multirow[t]{2}{*}{ CARR } & $0.074 \#$ & $0.382 \#$ & $0.580 \#$ & 0.962 & -1033.61 & 11.961 & 10.917 & 1.118 \\
\hline & $(0.016)$ & $(0.030)$ & $(0.034)$ & & & & & \\
\hline \multirow[t]{2}{*}{ CARR-B } & $0.120 \#$ & $0.171 \#$ & $0.452 \#$ & 0.623 & -1014.25 & 11.471 & 11.239 & 1.210 \\
\hline & $(0.024)$ & $(0.025)$ & $(0.054)$ & & & & & \\
\hline \multirow[t]{2}{*}{ GARCH } & $0.220^{*}$ & $0.137^{\star}$ & 0.832\# & 0.968 & -2413.54 & 12.902 & 6.758 & 0.672 \\
\hline & $(0.111)$ & $(0.061)$ & $(0.059)$ & & & & & \\
\hline \multirow[t]{2}{*}{ GARCH-B } & $0.747 \#$ & $0.110 \#$ & $0.602 \#$ & 0.711 & -2385.95 & 17.635 & 8.841 & 0.888 \\
\hline & $(0.305)$ & $(0.028)$ & $(0.113)$ & & & & & \\
\hline \multicolumn{9}{|l|}{ FTSE 100} \\
\hline \multirow[t]{2}{*}{ CARR } & $0.097 \#$ & $0.379 \#$ & $0.574 \#$ & 0.953 & -1198.93 & 12.393 & 11.518 & 0.613 \\
\hline & $(0.017)$ & $(0.037)$ & $(0.039)$ & & & & & \\
\hline \multirow[t]{2}{*}{ CARR-B } & $0.147 \#$ & $0.354 \#$ & $0.508 \#$ & 0.862 & -1186.43 & 11.923 & 11.819 & 0.711 \\
\hline & $(0.029)$ & $(0.039)$ & $(0.055)$ & & & & & \\
\hline \multirow[t]{2}{*}{ GARCH } & $0.265^{*}$ & $0.176 \#$ & $0.787 \#$ & 0.963 & -2423.61 & 6.658 & 12.371 & 1.305 \\
\hline & $(0.112)$ & $(0.044)$ & $(0.049)$ & & & & & \\
\hline \multirow[t]{2}{*}{ GARCH-B } & $0.498^{*}$ & $0.171 \#$ & 0.699\# & 0.870 & -2412.26 & 9.293 & 10.021 & 1.021 \\
\hline & $(0.232)$ & $(0.043)$ & $(0.085)$ & & & & & \\
\hline \multicolumn{9}{|l|}{ SZSEC } \\
\hline \multirow[t]{2}{*}{ CARR } & $0.037 \#$ & $0.101 \#$ & $0.877 \#$ & 0.978 & -1532.04 & 11.419 & 11.171 & 1.215 \\
\hline & $(0.005)$ & $(0.008)$ & $(0.008)$ & & & & & \\
\hline \multirow[t]{2}{*}{ CARR-B } & $0.045 \#$ & $0.106 \#$ & $0.742 \#$ & 0.848 & -1516.58 & 13.729 & 10.042 & 1.114 \\
\hline & $(0.009)$ & $(0.010)$ & $(0.012)$ & & & & & \\
\hline \multirow[t]{2}{*}{ GARCH } & $0.290^{*}$ & $0.128 \#$ & $0.854 \#$ & 0.982 & -2886.91 & 28.961\# & 3.063 & 0.303 \\
\hline & $(0.130)$ & $(0.024)$ & $(0.025)$ & & & & & \\
\hline \multirow[t]{2}{*}{ GARCH-B } & $0.314^{*}$ & $0.117 \#$ & $0.843 \#$ & 0.959 & -2881.85 & 26.629\# & 5.199 & 0.528 \\
\hline & $(0.169)$ & $(0.025)$ & $(0.032)$ & & & & & \\
\hline \multicolumn{9}{|l|}{ FBMKLCI } \\
\hline \multirow[t]{2}{*}{ CARR } & $0.028 \#$ & $0.268 \#$ & $0.726 \#$ & 0.994 & -663.40 & 10.319 & 10.200 & 0.816 \\
\hline & $(0.004)$ & $(0.018)$ & $(0.016)$ & & & & & \\
\hline \multirow[t]{2}{*}{ CARR-B } & $0.077 \#$ & $0.375 \#$ & $0.418 \#$ & 0.793 & -633.19 & 6.341 & 5.619 & 0.531 \\
\hline & $(0.009)$ & $(0.031)$ & $(0.031)$ & & & & & \\
\hline \multirow[t]{2}{*}{ GARCH } & 0.038 & $0.103 \#$ & $0.896 \#$ & 0.999 & -2378.57 & 14.831 & 2.077 & 0.202 \\
\hline & $(0.024)$ & $(0.025)$ & $(0.024)$ & & & & & \\
\hline \multirow[t]{2}{*}{ GARCH-B } & $0.060^{*}$ & $0.109 \#$ & $0.872 \#$ & 0.982 & -2373.83 & 15.416 & 2.383 & 0.233 \\
\hline & $(0.039)$ & $(0.034)$ & $(0.040)$ & & & & & \\
\hline
\end{tabular}

\# and ${ }^{*}$ mean significant at $1 \%$ and $5 \%$ levels respectively. The terms in the parenthesis (.) represent the standard error of the estimates. LLF represents the log-likelihood function, Q(10) and Qs(10) represent the Ljung Box statistic for standardized residuals and squared standardized residuals (respectively) up to 10 lags. $\mathrm{ARCH}(10)$ represent the ARCH-LM statistic for the presence of heteroscedasticity in the standardized residuals up to 10 lags. 


\subsection{Dynamic Impulse Response Function Based on the CARR, CARR-B, GARCH and GARCH-B Models}

Figure 1 presents the dynamic impulse response functions for the CARR, CARR-B, GARCH and GARCH-B models with a forecast horizon up to 30 weeks. Results indicate that the response to a unit shock experience smooth decay for CARR-B model than for the vanilla CARR model. However, the response to a unit shock experience quick decay for the GARCH-B model than the GARCH model. This supports the evidence that the persistence in conditional volatility based on the CARR-B model remains for a longer period than the persistence in volatility based on the GARCH-B model. This also indicates the importance of incorporating structural breaks in volatility while modelling and forecasting volatility.

\subsection{Out-of-Sample Volatility Forecast Comparison}

In this section, we assess the forecasting performance of the models under study based on 1 step ahead prediction of volatility. The forecasts are generated using rolling windows estimation of the models with fixed window size. We generate 500 forecasts for all the models and for all the indices. We use weekly realized volatility (sum of the square of daily returns) based as a proxy for measured volatility. We use the following four loss functions for evaluating the forecasting performance of models under study.

1) Root mean squared errors (RMSE)

$$
\operatorname{RMSE}(m, h)=\sqrt{\frac{1}{T} \sum_{t=1}^{T}\left(M V_{t+h}-F V_{t+h}(m)\right)^{2}}
$$

2) Mean absolute errors (MAE)

$$
\operatorname{MAE}(m, h)=\frac{1}{T} \sum_{t=1}^{T}\left|M V_{t+h}-F V_{t+h}(m)\right|
$$

3) Logarithmic loss function (LL)

$$
\operatorname{LL}(m, h)=\frac{1}{T} \sum_{t=1}^{T}\left(\ln \left(\frac{M V_{t+h}}{F V_{t+h}(m)}\right)\right)^{2}
$$

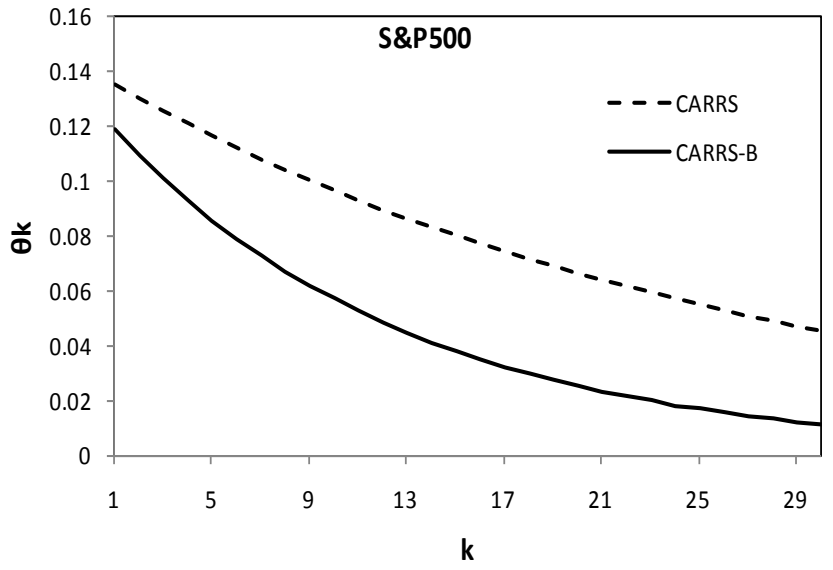

(a)

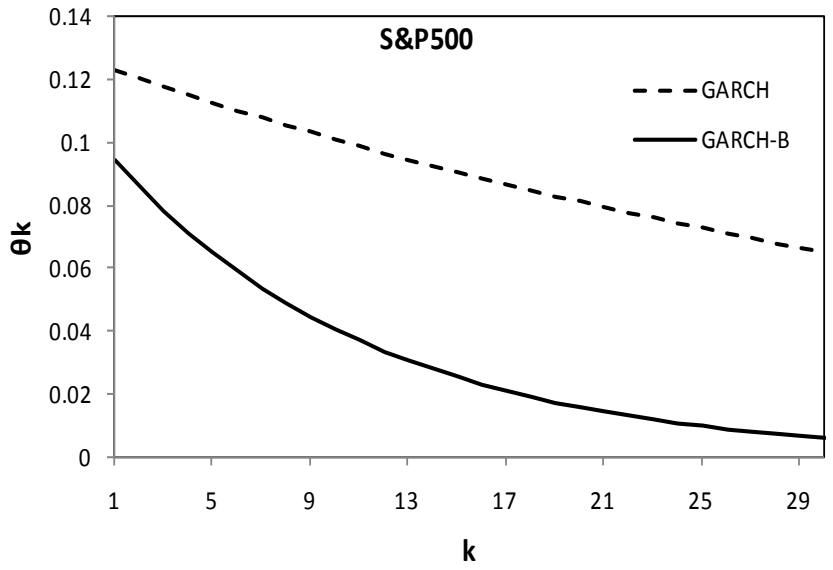

(b) 


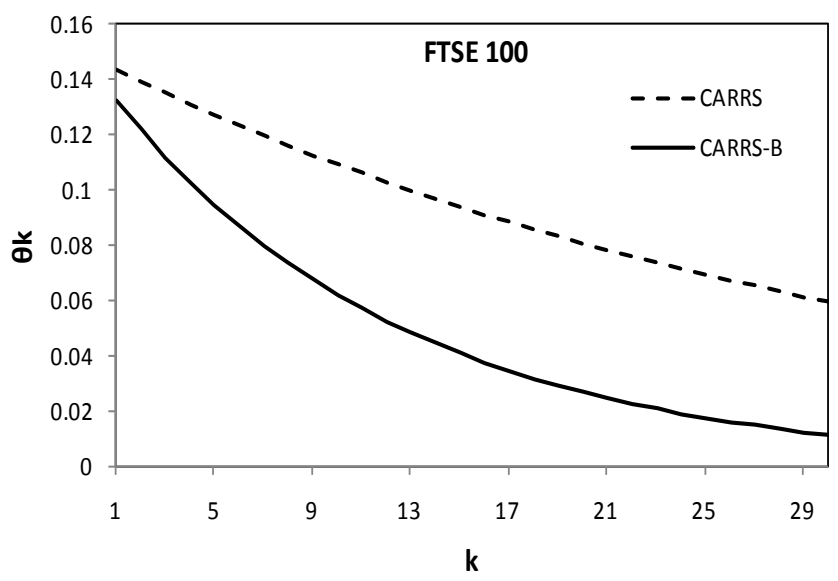

(c)

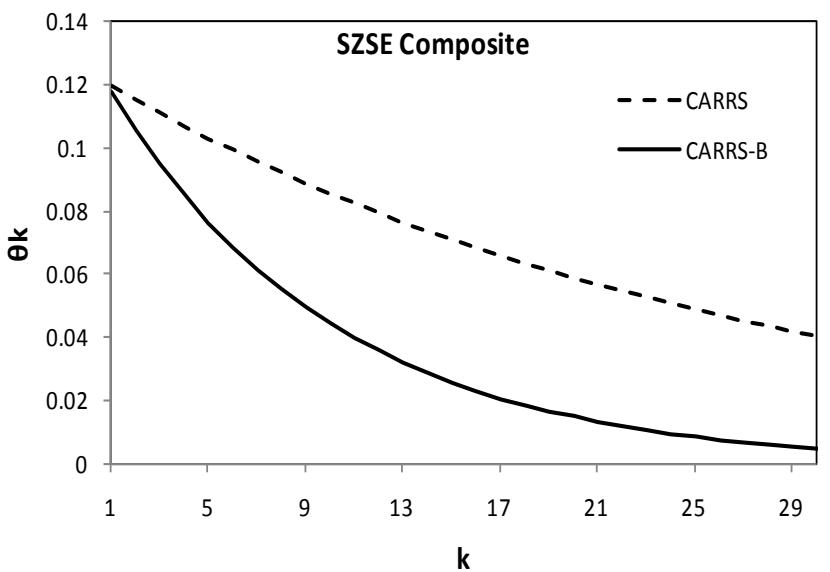

(e)

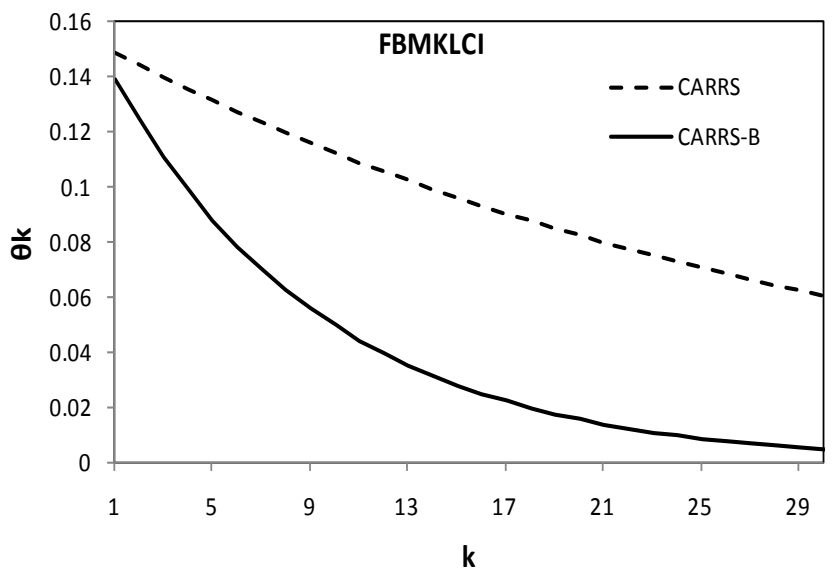

(g)

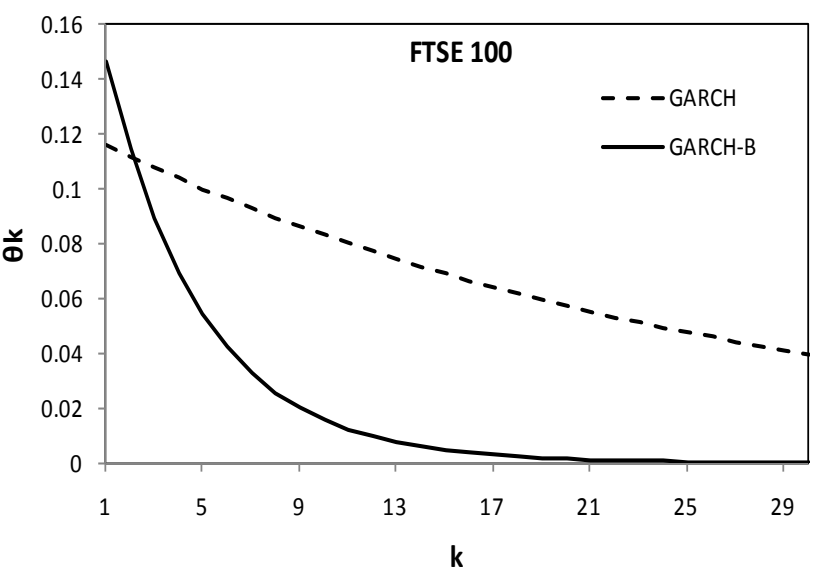

(d)

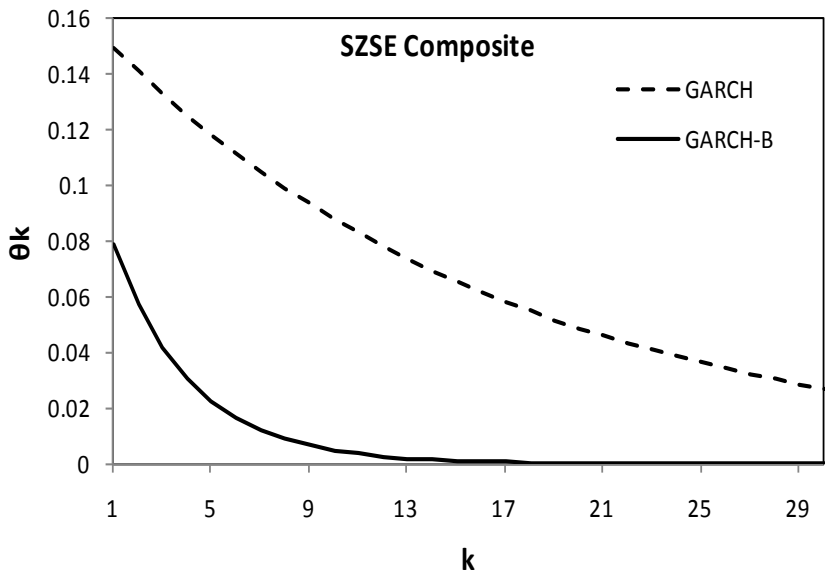

(f)

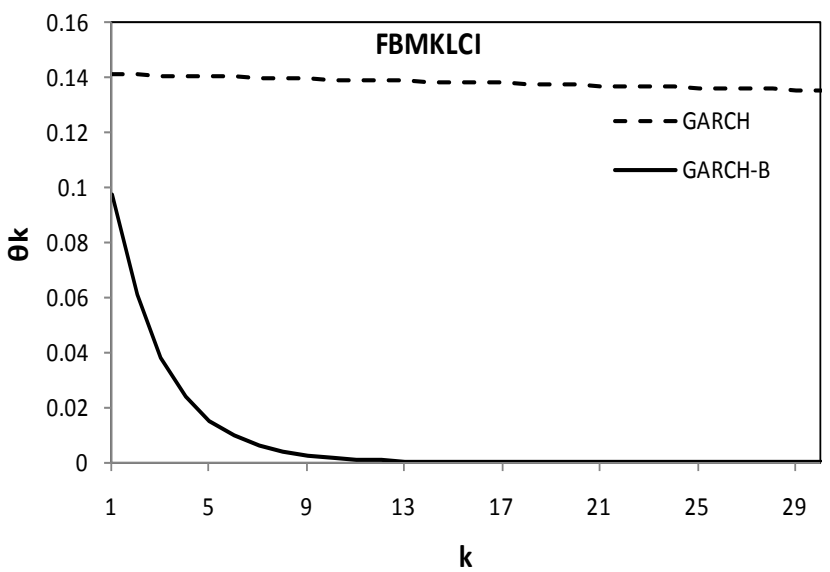

(h)

Figure 1. Dynamic impulse response function for the CARR and CARR-B models (left column) and the GARCH and GARCH-B models (right column).

4) Loss implied by Gaussian likelihood (QLIKE)

$$
\operatorname{QLIKE}(m, h)=\frac{1}{T} \sum_{t=1}^{T}\left(\ln \left(F V_{t+h}(m)\right)+\frac{M V_{t+h}}{F V_{t+h}(m)}\right)
$$


where $m$ represents the model (CARR-B, CARR, GARCH-B and GARCH), $h$ is equal to 1 representing 1 step ahead forecasts, $M V_{t}$ represents the measured volatility at time $t$ (realized volatility), $F V_{t}(m)$ represents the predicted volatility based on model $m$ and $T$ represents the number of out-of-sample volatility forecasts. Here, $T$ is 500 .

Table 5 reports the forecast evaluation results for all the models and indices under study. Results indicate that for all the indices, the CARR-B model provides more accurate forecasts than other models under consideration. Moreover, the CARR model is at the second position to provide more accurate forecasts of realized volatility for all the indices under study. The error statistics value is quite high for both GARCH-B and GARCH models in comparison to CARR-B and CARR models.

\subsection{Volatility Forecast Evaluation Based on Mincer and Zarnowitz [20] Regression}

In addition to the error statistics, we also use Mincer and Zarnowitz [20] regression-based approach to evaluate the ability of the models under study to generate more accurate forecasts of volatility. The regression model used is given as:

$$
M V_{t+h}=\alpha+\beta F V_{t+h}(m)+\varepsilon_{t}
$$

where $M V_{t}$ represents the measured volatility (realized volatility) at time $t$, $F V_{t}(m)$ is a predicted volatility based on model $\mathrm{m}$ and $\varepsilon_{t}$ represents the error term. Table 6 reports the $R^{2}$ of the Mincer and Zarnowitz [20] regression equation and it measures the total variation in realized volatility explained by the predicted volatility. Results clearly indicate that the $R^{2}$ based on the CARR-B's predicted volatility is the highest for all the indices indicating the superior ability of the CARR-B model in generating more accurate forecasts of the volatility.

\subsection{Trading Strategy to Study the Economic Significance of the Study and Policy Implications}

To examine the economic significance of the findings of the study, we implement a trading strategy based on the risk-averse investor who uses predicted volatility to switch investment between a portfolio of risky stocks (given index) and a risk-free asset. The risk-free assets for a country is the 3 months (for the USA and the UK) or 6 months (for China and Malaysia) T-Bills of that economy. For bad news (negative return and if forecasted volatility is greater than average volatility), the investor invests $100 \%$ of the capital in the risk-free asset or else he invests in the portfolio of risky stocks. Table 7 reports the average annual return earned the risk average investor in the given market. It can be seen that the highest average return can be earned by using the volatility forecasts of the CARR-B. The volatility forecasts based on the CARR model also provide a slightly less average annualized return in comparison to the corresponding returns earned by using the volatility forecasts of the CARR-B model. The average 
Table 5. Out-of-sample volatility forecast evaluation.

\begin{tabular}{ccccc}
\hline & CARR & CARR-B & GARCH & GARCH-B \\
\hline S\&P 500 & & & & \\
\hline MSE & 2.663 & 2.602 & 8.484 & 2.553 \\
MAE & 1.103 & 1.063 & 5.686 & 1.411 \\
LL & 1.351 & 1.329 & 6.077 & 1.963 \\
QLIKE & 2.407 & 2.339 & 15.826 & 3.869 \\
\hline FTSE 100 & & & & \\
\hline MSE & 3.380 & 3.335 & 9.266 & 16.431 \\
MAE & 1.323 & 1.279 & 6.405 & 11.388 \\
LL & 1.267 & 1.219 & 5.276 & 5.947 \\
QLIKE & 2.400 & 2.295 & 12.483 & 17.117 \\
\hline SZSEC & & & & \\
\hline MSE & 2.830 & 2.812 & 22.399 & 22.399 \\
MAE & 1.463 & 1.417 & 15.093 & 15.093 \\
LL & 1.180 & 1.114 & 7.466 & 7.466 \\
QLIKE & 2.465 & 2.329 & 22.060 & 22.060 \\
\hline FBMKLCI & & 1.279 & & \\
\hline MSE & 0.891 & 0.792 & 4.926 & 2.650 \\
MAE & 0.415 & 0.345 & 3.358 & 15.076 \\
LL & 1.615 & 1.335 & 7.840 & \\
\hline QLIKE & 1.998 & 150.024 & \\
\hline & & & & \\
\hline & & & & \\
\hline & & & & \\
\hline & & & & \\
\hline
\end{tabular}

Table 6. The $\mathrm{R}^{2}$ based on the Mincer and Zarnowitz [20] regression model.

\begin{tabular}{ccccc}
\hline & CARR & CARR-B & GARCH & GARCH-B \\
\hline S\&P 500 & 0.407 & 0.418 & 0.286 & 0.295 \\
FTSE 100 & 0.227 & 0.312 & 0.299 & 0.158 \\
SZSEC & 0.224 & 0.230 & 0.184 & 0.184 \\
FBMKLCI & 0.088 & 0.089 & 0.087 & 0.088 \\
\hline
\end{tabular}

Table 7. Average annual return (\%) for the risk-averse investor.

\begin{tabular}{ccccc}
\hline & CARR & CARR-B & GARCH & GARCH-B \\
\hline S \& P 500 & 8.396 & 9.732 & 4.961 & 5.193 \\
FTSE 100 & 4.106 & 4.817 & -2.167 & 3.851 \\
SZSEC & 4.219 & 5.151 & 1.518 & 1.518 \\
FBMKLCI & 5.316 & 6.473 & 2.153 & 4.619 \\
\hline
\end{tabular}

annualized return based on the GARCH and GARCH-B models are quite low and for the case of FTSE 100, the volatility forecasts based on the GARCH model provides a negative average annualized return for the risk-averse investor. 
The findings of the study have implications towards policy maker, regulators, traders, risk managers, portfolio managers and investors. The study highlights the importance of incorporating structural breaks in volatility in modelling and in generating more accurate forecasts of volatility. The findings based on economic return earned by the risk-averse investor provide implication of the study for investors, traders and portfolio managers. Policy makers and regulators can use the unbiased AddRS volatility estimator in presence of structural breaks to understand the periods of stability and turbulence in the market and to implement appropriate policies to deal with the adverse impact of any macroeconomic event. Moreover, more accurate forecasts of volatility in deriving more accurate Value-at-Risk and Expected Shortfall measures to quantify risk and has implications for risk managers.

\section{Conclusion}

In this study, we propose the use of the CARR model to model the AddRS estimator and to generate a more accurate forecast of it. We also incorporate the impact of structural breaks in volatility in CARR model while modelling and forecasting the AddRS estimator. The results based on the in-sample estimation and impulse response support the evidence that incorporating the impact of structural breaks in volatility modelling does decrease the volatility persistence. We observe that this decrease in volatility persistence is smooth for CARR-B model. We observe an abrupt decrease in volatility persistence for the GARCH-B model. The results based on out-of-sample volatility forecast evaluation indicate that the CARR-B model provides more accurate forecasts of realized volatility when compared with corresponding volatility forecasts by another model. The economic significance analysis also indicates that the risk-averse investor can earn a higher average annualized return by trading based on the volatility forecasts of the CARR-B model. Overall, our finding indicates that the CARR-B model outperforms other models in generating more accurate forecasts of realized volatility.

\section{References}

[1] Kumar, D. and Maheswaran, S. (2014) A Reflection Principle for a Random Walk with Implications for Volatility Estimation Using Extreme Values of Asset Prices. Economic Modelling, 38, 33-44. https://doi.org/10.1016/j.econmod.2013.11.045

[2] Alizadeh, S., Brandt, M.W. and Diebold, F.X. (2002) Range-Based Estimation of Stochastic Volatility Models. The Journal of Finance, 57, 1047-1091. https://doi.org/10.1111/1540-6261.00454

[3] Parkinson, M. (1980) The Extreme Value Method for Estimating the Variance of the Rate of Return. Journal of Business, 53, 61-65. https://doi.org/10.1086/296071

[4] Garman, M.B. and Klass, M.J. (1980) On the Estimation of Security Price Volatilities from Historical Data. Journal of Business, 53, 67-78. https://doi.org/10.1086/296072

[5] Rogers, L.C.G. and Satchell, S.E. (1991) Estimating Variance from High, Low and 
Closing Prices. The Annals of Applied Probability, 1, 504-512. https://doi.org/10.1214/aoap/1177005835

[6] Yang, D. and Zhang, Q. (2000) Drift-Independent Volatility Estimation Based on High, Low, Open, and Close Prices. The Journal of Business, 73, 477-492.

https://doi.org/10.1086/209650

[7] Kumar, D. and Maheswaran, S. (2012) Modelling Asymmetry and Persistence under the Impact of Sudden Changes in the Volatility of the Indian Stock Market. IIMB Management Review, 24, 123-136. https://doi.org/10.1016/j.iimb.2012.04.006

[8] Babikir, A., Gupta, R., Mwabutwa, C. and Owusu-Sekyere, E. (2012) Structural Breaks and GARCH Models of Stock Return Volatility: The Case of South Africa. Economic Modelling, 29, 2435-2443. https://doi.org/10.1016/j.econmod.2012.06.038

[9] Rapach, D.E. and Strauss, J.K. (2008) Structural Breaks and GARCH Models of Exchange Rate Volatility. Journal of Applied Econometrics, 23, 65-90. https://doi.org/10.1002/jae.976

[10] Salisu, A.A. and Fasanya, I.O. (2013) Modelling Oil Price Volatility with Structural Breaks. Energy Policy, 52, 554-562. https://doi.org/10.1016/j.enpol.2012.10.003

[11] Ross, S.A. (1989) Information and Volatility: The No-Arbitrage Martingale Approach to Timing and Resolution Irrelevancy. The Journal of Finance, 44, 1-17. https://doi.org/10.1111/j.1540-6261.1989.tb02401.x

[12] Kumar, D. and Maheswaran, S. (2013) Evidence of Long Memory in the Indian Stock Market. Asia-Pacific Journal of Management Research and Innovation, 9, 9-21. https://doi.org/10.1177/2319510X13483504

[13] Inclan, C. and Tiao, G.C. (1994) Use of Cumulative Sums of Squares for Retrospective Detection of Changes of Variance. Journal of the American Statistical Association, 89, 913-923.

[14] Chou, R.Y.T. (2005) Forecasting Financial Volatilities with Extreme Values: The Conditional Autoregressive Range (CARR) Model. Journal of Money, Credit, and Banking, 37, 561-582. https://doi.org/10.1353/mcb.2005.0027

[15] Brandt, M.W. and Jones, C.S. (2006) Volatility Forecasting with Range-Based EGARCH Models. Journal of Business \& Economic Statistics, 24, 470-486. https://doi.org/10.1198/073500106000000206

[16] Kumar, D. (2015) Sudden Changes in Extreme Value Volatility Estimator: Modeling and Forecasting with Economic Significance Analysis. Economic Modelling, 49, 354-371. https://doi.org/10.1016/j.econmod.2015.05.001

[17] Li, H. and Hong, Y. (2011) Financial Volatility Forecasting with Range-Based Autoregressive Volatility Model. Finance Research Letters, 8, 69-76. https://doi.org/10.1016/j.frl.2010.12.002

[18] Lamoureux, C.G. and Lastrapes, W.D. (1990) Persistence in Variance, Structural Change, and the GARCH Model. Journal of Business \& Economic Statistics, 8, 225-234.

[19] Malik, F. (2003) Sudden Changes in Variance and Volatility Persistence in Foreign Exchange Markets. Journal of Multinational Financial Management, 13, 217-230. https://doi.org/10.1016/S1042-444X(02)00052-X

[20] Mincer, J. and Zarnowitx, V. (1969) The Evaluation of Economic Forecasts, Economic Forecasts and Expectations (NBER). Columbia University Press, New York, 3-46. 